conclusively attested by the evidence of the gentleme whose statements I have quoted.

I am indebted to Sir Dighton Probyn for an interesting letter from Capt. Gerard, of Goona, a high authority on Indian felidx. He expresses his belief that tigers seldom if ever exceed Jerdon's measurements, a tiger of 10 feet I inch being the length of the largest he has ever killed or seen. He refers to examples of large tigers described by various observers, but he doubts the accuracy of the measurements, which he thinks may have been unintentionally exaggerated. His own experience is very large, his accuracy as an observer well known, and his opinion consequently of much value; but it is hardly sufficient to invalidate that of others who are no less competent to note and record facts, and who certainly give a greater length, as the extreme growth of the tiger, than that within which Capt. Gerard limits him. The matter then stands thus : Mr. C. Shillingford, Col. G. Boileau, and Sir C. Reid, ${ }^{1}$ vouch for tigers of over i2 feet. The same gentlemen, with Sir H. Green, Sir G. Yule, the Hon. R. Drummond, Col, D. G. Stewart, Mr. Cumming, and Col. Shakespeare vouch for tigers of II feet and upwards. The above, with Col. J. Sleeman, Sir Joseph Fayrer, Mr. B. Simson, and the Hon. Sir H. Ramsay vouch for tigers of ro feet 5 inches and upwards, all from measurements taken before the animals were skinned. Unless these gentlemen, all of whom are accustomed to shoot and measure tigers, were mistaken, the question of length may, I think, be regarded as decided beyond dispute.

In conclusion, after thanking sincerely those gentlemen who have given me information derived from their own experience, I would just say that the mere length of a tiger is not necessarily an indication of its real size. The tail is included in the measurement-so tiger hunters have ruled that it shall be-but the tail is a somewhat variable element; in some it is long, in others short, and it is quite possible that a 9 -foot 6 -inch tiger with a short tail may be heavier, stronger, and larger than a Io-foot tiger with a long tail. No doubt anything over Io feet is very large, and those of II or I2 are rare and exceptional, even though part of their great length may be assigned to an immensely long tail. But I think that, while making all allowances for errors of measurement-which doubtless are not uncommon, though unintentional--there is still sufficient evidence from accurate measurements to show that tigers may exceed Io feet 3 inches, and that a few-perhaps rare and exceptional instances-do exceed even II and iz feet.

J. FAYRER

\section{THE TELEPHONE, ITS HISTORY AND ITS RECENT IMPROVEMENTS ${ }^{1}$}

$$
\text { II. }
$$

I $\mathrm{N}$ the preceding article we traced the history and development of the magneto-telephone. This instrument, even if it served no other purpose, has given to physicists a galvanoscope of surpassing delicacy. In the columns of this journal (vol. xvii. p. 343) Prof. Forbes showed how the feeblest thermo-electric currents could be detected by its means, whilst the subsequent discovery of the microphone was but another application of the same fact. This latter instrument and the early history of the carbon telephone we now propose to consider.

In the spring of the present year Mr. W. H. Preece startled every one by announcing that Prof. Hughes, the well-known inventor of the type-printing telegraph, had discovered that a couple of bits of charcoal, or a few fragments of metal in loose contact, when in circuit with

I Since writing the above I have been informed by General Sir C. Reid, K.C. B. Bengal Army, that he has shot, and measured before the skin was removed, in the Dhoon a tiger of 12 feet 3 inches.

removed, in the Dhoon a tiger of 12 feet 3 inches. by G. B. Prescott. Illustrated. (New York, Appletons, 1878.)-"Le Ty G. B. Prescott. Hone, le Microphoue, et le Phonographe," par Le Conte Th. du Moncel. (Hachette, $1 \varepsilon_{7} 8$.) Continued from vol, xviii. p. 700 . a telephone and a voltaic cell, were able to reveal the faintest tremor or even to transmit the sound of the voice itself. Universal interest was excited by this discovery; a direct transformation of sonorous vibrations into electricity was supposed to have been discovered, but soon it became apparent that the explanation originally suggested was untenable, and that the true theory of the microphone was to be found in minute variations of current strength. The quivering of the loose fragments produced variable degrees of contact or of pressure, and the marvellous sensitiveness of the magneto-telephone revealed these otherwise inappreciable fuctuations in the resistance of the circuit.

On account of its sensitiveness, the microphone has been suggested as likely to be of use in auscultation. ${ }^{1} \mathrm{M}$. diz Moncel gives a form of stethoscopic microphone made by M. Ducretet, and shown in Fig. 2. The microphone pencil, $C$, rests upon a lower plate of carbon, $\mathrm{p}$, which is adapted to a caoutchouc capsule, $\mathrm{T}$, and this again is connected by a flexible tube to a second capsule, $T^{\prime}$, which can be applied to different parts of the body of the patient. Although the sensibility of the microphone can to some extent be regulated by the counterpoise, $P$ O, yet still the objection to this apparatus is its over sensibility, for it reveals every noise or tremor, so that it is difficult to distinguish one sound from another. It is not impossible, however, that this or some other arrangement of the microphone may ultimately be found to yield important results in the hands of a physician who has made himself skilled in its use. At the same time we must bear in mind that, after its employment in a surgical case by Sir H. Thompson, the large expectations that were formed of the microphone as an exploring instrument in surgery have not as yet been fulfilled. We are not aware whether the microphone has been tried by seismologists, or by military men to detect the mining operations of an enemy, though we should fear the same causes that operate against it elsewhere might also occur wherever it is employed. The disturbances to which the instrument is subject are most conspicuous when the microphone is used, as it can be, to transmit speech. Nevertheless a particular arrangement, designed by Mr. Hughes (Fig. 3), gives fair results. The two. fragments of carbon are shown at $C D$, the upper one being attached to a light metal arm $A$, controlled by a spring $\mathrm{R}$, the tension of which is regulated by a screw $t$. The whole is inclosed in a light wooden box $\mathrm{H}^{\prime} \mathrm{I}$ G, surrounded by a second box $M \mathrm{~J} L$, the end of which is left open. A single carbon only, may even be used, touching the metal arm, as is shown at $\mathrm{E}$. In this case the carbon is supported by a strip of paper gummed to. the bottom of the box. Loid as is the articulation transmitted by means of this arrangement, the noisy roar which accompanies it, from tremors picked up by carbons, render many words quite inaudible in the receiving telephone. So far, in fact, the microphone bas not proved a practical instrument; it seems, however, likely to become a useful adjunct in physical or physico-chemical researches. In any case science is indebted to Prof. Hughes for first making known an entirely novel, simple, and delicate instrument for the detection of minute mechanical motions.

We say first making known, for some twelve months. before Prof. Hughes published his description of the microphone, an arrangement designed by Mr. Edison was singularly like the microphone in its extreme delicacy to the minutest tremor. A couple of inches of silk ribbon rubbed with plumbago and made stiff with gum, was laid upon two metal supports joined in circuit with a telephone and a small battery. Such an arrangement not only de-

I Apropos of the microphone a literary friend sends me the following extract from an ancient Turkish tract containing an exposition of the Moslems creed:- "He (Allah) hears alike the loudest and gentlest sounds and sees all things, even the waiking in a dark night of a black ant on a black stone, wid hears the treading of its feet, and this without eyes or ears." 
tected the slightest vibration but was capable of transmitting speech with remarkable loudness. Although this result has hitherto been unpublished, an application of the same principle was made by Mr. Edison in his "carbon relay," a reprint account of which was published in the Telegraphic Journal for July I, 1877, and the simple form of this relay (Fig. 4) resembles in construction and in principle the so-called hammer and anvil microphone. Edison's carbon rheostat, lately illustrated in our pages, also depends upon the same principle, namely, the compression of a semi-conductor, such as carbon, increasing its conductivity, a diminution of pressure increasing the resistance. It is true that it has been suggested that a rheostat of this kind was made by $M$. Clérac in 1865 , but so far as we have been able to ascertain, no mention is made of varying pressure in the use of Clérac's instrument, but simply the difference in the resistance of columns of plumbago of varying length.

The curious effect of pressure on the electric resistance of semi-conductors was noticed so long ago as 1856 by $M$. du Moncel, who wrote as follows in the second edition of his "Exposé des Applications de l'Electricité" (vol. i. p. 246) :"Une chose assez curieuse, et qui paraît être au premier abord en contradiction avec la théorie que l'on s'est faite de l'électricité, c'est que la plus ou moins grande pression exercée entre les pièces de contact des interrupteurs influe considérablement sur l'intensité du courant qui les traverse. Cela tient souvent à ce que les métaux de l'interrupteur ne sont pas toujours dans un état parfait de décapage au point de contact, mais, peut-être aussi à une cause physique encore mal appréciée." Subsequently, in an elaborate memoir on the electric conductivity of bodies, the same distinguished author wrote:- "La pression exercée sur les electrodes joue un grand rôle sur la conductibilité de celui-ci quand il est susceptible d'une certaine compression, comme les bois, les corps mous et pâteux et ceux qui sont réduits à un grand état de division." In 1873 Edison states (Prescott, p. 223) that he independently discovered "the peculiar property which semi-conductors have of varying their resistance with pressure while constructing some rheostats for artificial cables, in which were employed powdered carbon, plumbago, and other materials in glass tubes."

In January, 1877, Edison states that he first applied to telephonic purposes the effect of pressure on carbon. It will be remembered that the principle of Gray's telephone was the variations in the resistance of a liquid, proportional to the motions of a diaphragm vibrated by the voice, but that the decomposition of the Iiquid by the current introduced practical difficulties in the working of this arrangement. Casting about for a means of overcoming this difficulty, Edison recalled his early observations on the electrical properties of carbon, and, encouraged by his preliminary trials, was led onwards step by step, his unwearied efforts being at last crowned by the construction of his carbon telephone, towards the close of last year. In another article we shall trace the evolution and present achievements of the carbon telephone, an instrument which we believe is destined to have a great future.

In conclusion, it is interesting to note that "just as Gray and Bell were both led to the discovery of the principle of an articulating telephone through working at the important problem of multiple telegraphy, or the simultaneous transmission of several different signals on one wire, so, too, Edison travelled in the same direction. In Prescott's work he writes: "Some time in or about July, I 875 , I began experimenting with a system of multiple telegraphy which had for its basis the transmission of acoustic vibrations." His transmitters were a chord of tuning-forks maintained in vibration by the action of a current; the current not being interrupted at each vibration, but made to vary in strength: his, receivers consisted of electro-magnets acting upon iron diaphragms, which closed the end of a series of resonant tubes. In practice difficulties arose, but the system contained two important features. These were, first, the employment of undulatory electric
currents, an electrode attached to one prong of the trans-

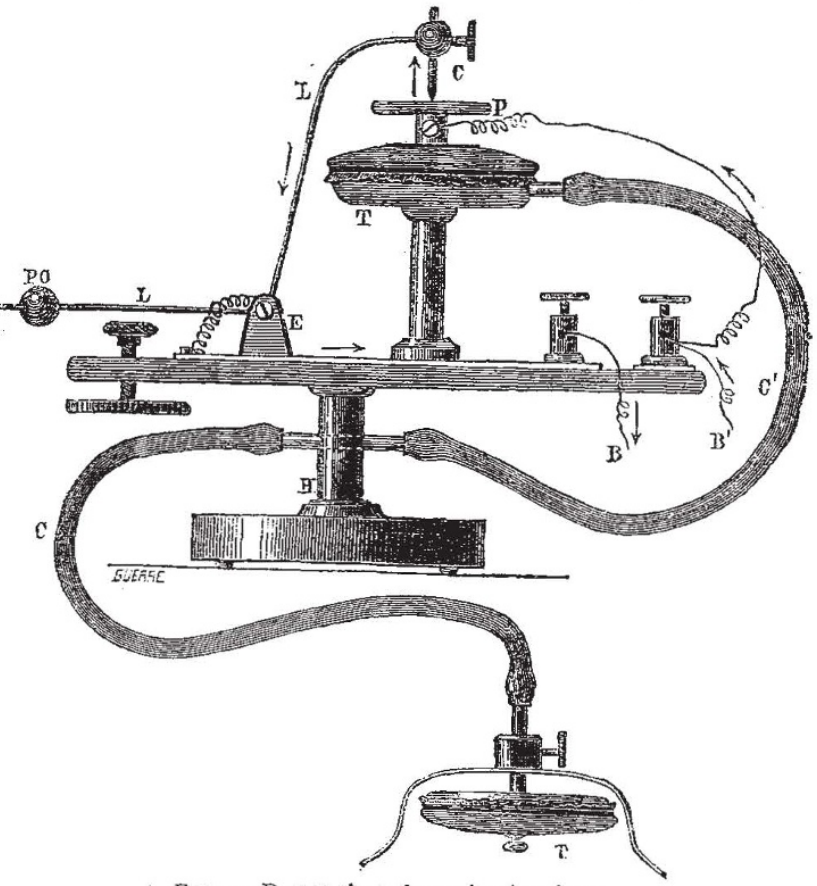

FIG. 2,-Ducretet's stethoscopic microphone.

mitting fork being made to vary the resistance of the circuit by vibrating in a vessel of water, an idea which Edison claims to have patented as early as 1873 ; and the second is the use of an iron diaphragm and adjacent electro-magnet as a receiver. Substituting a membrane moved by the voice, the transmitter becomes the same as that patented by Gray in 1876 , and the receiving instrument is similar to that used in the magneto-speak-

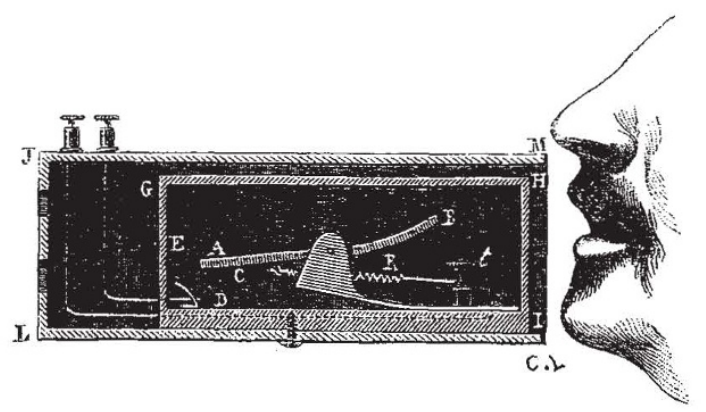

FIG. 3.-Hammer and anvil microphone as arranged for transmitting speech.

ing or Bell's telephone. Hence, if these facts are unassailable, and the latter is at present the subject of litigation in America, to Edison is also due the happy inspiration of first using a thin iron diaphragm as a receiver. At the same time Edison, in a recent letter to the present writer, remarks, "Bell had the merit of discovering such a receiver would act as a transmitter," and likewise in 
Prescott's book, Edison distinctly says: "I can lay no claim to having discovered that conversation could be carried on between one receiver and the other upon the magneto-principle, causing the voice to vibrate the diaphragm. . . My first attempts at constructing an articulating telephone were made with a Reis transmitter and one of my resonant receivers. My experiments in this direction, which continued until the production of my present carbon telephone, cover many thousand pages of manuscript."

This last incidental remark, which there is no reason to doubt, reveals the indefatigable character of the man. The public see only the successful results, and many doubtless imagine that these spring ready accomplished from the fertile brain of Mr. Edison; the truth is just the reverse. It is a trite, but true observation, that successful work in any direction, and notably in scientific discovery, is the result of patient persistent toil. The public look at the nugget, but not at the labour that has won it. The fields of science are now so well trodden that

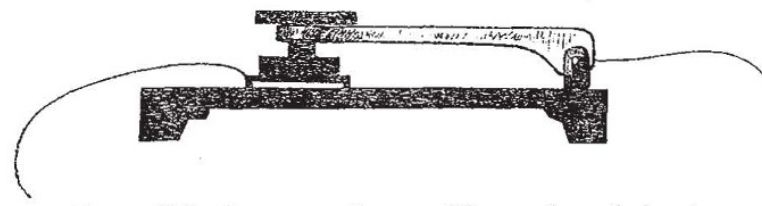

Fig. 4--Edison's pressure relay resembling cne form of microphone.

discoveries are not to be accidentally picked up, but only reward those whose quest is most skilful and diligent.

The extraordinary succession of valuable discoveries in applied science which $\mathrm{Mr}$. Edison has made can only be the offspring of incessant work, profound technical knowledge, and that ready resource under difficulties which characterises a mechanical genius. The conditions under which such a man works are different from those of a purely scientific investigator; the latter publishes his researches and thereby establishes his claim to the priority of the work he has done; the former can publish nothing till the end he has in view is achieved, and the pecuniary benefit accruing from his labours secured by legal processes. And because the reward sought in the two cases is very different, the investigator must often expect to see others reaping the benefit of applications that may be made of his observations, and the inventor ought not to grumble when he finds others claiming credit for work he may previously have done, but for his purpose found it necessary to keep by him unpublished.

W. F. BARRETT

\section{OUR ASTRONOMICAL COLUMN}

The late Solar Eclipse at Watson's Station.Frof. Watson made such excellent use of the brief period of totality in the eclipse of July 29 , that it will not be without interest to record the circumstances under which he observed. In a communication to M. Mouchez he gives for his position at Separation, Wyoming Territory, latitude $41^{\circ} 45^{\prime} 50^{\prime \prime}$, longitude $2 \mathrm{~h}$. $1 \mathrm{~m}$. $36 \mathrm{~s}$. west of Washington, corresponding to $7 \mathrm{~h} .9 \mathrm{~m}$. 48 Is., west longitude from Greenwich. Prof. Newcomb's corrections to Hansen's place of the moon at this time are $-0.63 \mathrm{~s}$. in right ascension, and $+3.3^{\prime \prime}$ in declination; whence if we take Ioh. $24 \mathrm{~m}$. Greenwich M.T. for a special calculation, we have for the position of the moon, R.A. 8 h. $38 \mathrm{~m}$. 11' $96 \mathrm{~s}$., decl. + $19^{\circ} 5^{\prime} 59^{\circ} 3^{\prime \prime}$. Combining this with the sun's place from Leverrier's Tables and the Nautical Almanac semidiameters, there results

Beginning of total eclipse, July $29 \cdots 3$ h. 13m. $32 \cdot 5$ \} Mean times Ending $\quad . . \quad \ldots \quad \ldots \quad \ldots 3 \mathrm{~h} .16 \mathrm{~m} .24^{\circ} \mathrm{o}$ at Separation,

Thus the duration of totality was $2 \mathrm{~m} \cdot 5 \mathrm{r} \cdot 5 \mathrm{~s}$.

If for the Nautical Almanac values we substitute
Leverrier's semi-diameter for sun and deduce the semidiameter of the moon from her horizontal parallax with Burckhardt's ratio, we find the times of beginning and ending of totality are respectively $3 \mathrm{~h}$. $13 \mathrm{~m}$. $32^{\circ} \mathrm{Os}$. and $3 \mathrm{~h} .16 \mathrm{~m} .24^{\circ} 5 \mathrm{~s}$, showing a duration of $2 \mathrm{~m} .52 .5 \mathrm{~s}$. ; we may therefore take $2 \mathrm{~m}$. $52 \mathrm{~s}$. for the interval which was available to Prof. Watson in his search for intra-mercurial planets. The middle of totality occurred at 3h. I4s. 58.35. M.T. at Separation, or at ish. $44 \mathrm{~m}$. 4I'9s. sidereal time, when the sun's altitude was $44 \frac{1}{2}^{\circ}$, and his hour-angle $46 \frac{1}{2}^{\circ} \mathrm{W}$.

Calculation of ExCentric Anomalies. - The number of bodies in the minor planet group is now approaching two hundred, yet so far as their orbits have been satisfactorily determined only two or three out of this number have the angle of excentricity, as it is termed, or $\sin ^{-1} x_{e}$, greater than $20^{\circ}$, which corresponds to $e=0.342$. More than ten years since Mr. Godward, of the Nautical Almanac Office, prepared some tables for the direct computation of the excentric anomaly from the mean to this limit of excentricity. His process is as follows :- -

In orbits where the excentricity is not great, $M, w$, and $v$ being the mean, excentric and true anomalies respectively, and $\phi$ the angle of excentricity$\tan \frac{1}{2} v=\tan ^{2}\left(45^{\circ}+\frac{1}{2} \phi\right) \tan \frac{1}{2} M$ nearly.

Let $M^{\prime}$ be an angle such that

$$
\begin{aligned}
\tan \frac{1}{2} v & =\tan \left(45^{\circ}+\frac{\pi}{2} \phi\right) \tan \frac{1}{2} u \\
& =\tan ^{2}\left(45^{\circ}+\frac{2}{2} \phi\right) \tan \left[\frac{1}{2} M+\frac{1}{2}\left(M^{\prime}-M\right)\right] .
\end{aligned}
$$

Then the Table contains $\frac{1}{2}\left(M^{\prime}-M\right)$ for any value of $\phi$ up to $20^{\circ}$, the arguments being $\frac{1}{2} M$ and $\frac{1}{2} \phi$.

As an example of the use of this Table, suppose the excentric anomaly of Juno is required for the time to which the elements of the planet are reduced in the Appendix to the Nautical Almanac for I88r. The mean anomaly $(=\epsilon-\pi)=168^{\circ} 39^{\prime} 43$ and $\frac{1}{2} \phi=7^{\circ} 23^{\prime} \cdot 22$, then

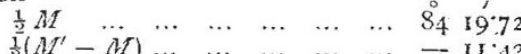

$$
\begin{aligned}
& \begin{array}{lllllllll}
\frac{1}{2} M^{\prime} & \ldots & \ldots & \ldots & \ldots & \ldots & \ldots & 84 & 8 \cdot 30
\end{array} \\
& \begin{array}{lllllll}
\tan \frac{1}{2} M^{\prime} & \ldots & \ldots & \ldots & \ldots & \ldots & 0.98858
\end{array}
\end{aligned}
$$

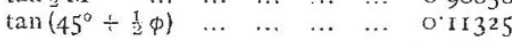

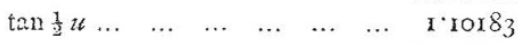

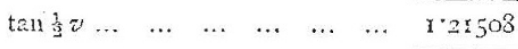

$$
\begin{aligned}
& \begin{array}{llllllllll}
\frac{1}{3} u & \ldots & \ldots & \ldots & \ldots & \ldots & \ldots & 8_{5}^{\circ} & 28 & 6
\end{array} \\
& \begin{array}{lllllllll}
\frac{1}{2} v & \ldots & \ldots & \ldots & \ldots & \ldots & \ldots & \$ 6 & 30 \\
& 74
\end{array} \\
& \begin{array}{llllllllll}
26 & \ldots & \ldots & \ldots & \ldots & \ldots & \ldots & \ldots & \mathrm{I} 70 & 57.28
\end{array} \\
& \begin{array}{llllllllll}
\approx & \ldots & \ldots & \ldots & \ldots & \ldots & \ldots & \ldots & \text { I } 73 & \text { I } 48
\end{array}
\end{aligned}
$$$$
\begin{array}{llllllll} 
& \ldots & \ldots & \ldots & \ldots & \ldots & - & -1
\end{array}{ }^{4} 2 \text { from the Table. }
$$

Here $\tan \frac{1}{2} \sigma$ is obtained by adding together the two previous lines, so that there is no subtraction in the operation.

Mr. Godward's Table was printed by the Nautical Almanac Office in 1866. It is applicable to all the satellite-orbits showing excentricity, as Hyperion, where $\phi=7^{\circ} \mathrm{II}^{\prime}$.

The Minor Planets.-From No. 100 of the Circular zuml Berliner astronomischen Jahrbuch it appears that the small planet at first announced as No. 190 is proved by Herr Leppig's calculation of its orbit to be identical with No. 94 (Aurora); the succeeding discovery therefore takes its number, and for planets found since the beginning of the summer, the numbers, names, and dates will stand thus :--

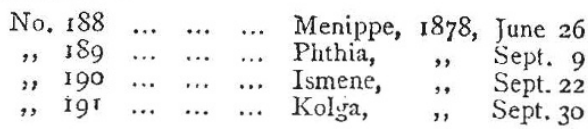

